\title{
El reto de la paridad en las candidaturas
}

\section{María del Carmen Alanis*}

\section{Sumario:}

I. Introducción

II. Política de paridad

III. Reformas a nivel federal

IV. Reformas a nivel local

V. A manera de conclusión

VI. Bibliografía

* Doctora en derecho y magistrada de la Sala Superior del Tribunal Electoral del Poder Judicial de la Federación. 


\section{Resumen:}

El artículo analiza las reformas constitucional y legales, a nivel federal y local, sobre la implementación de la paridad de género en las candidaturas. Se prevén los escenarios que permitirían dar mayor efectividad en el acceso de las mujeres a los cargos de representación popular.

Se estudian las posibilidades que surgen de las reformas legislativas emprendidas por las entidades federativas que tendrán elecciones en 2015. El hallazgo principal es que se prevé un incremento significativo en los niveles de representación de mujeres en los ayuntamientos.

\begin{abstract}
:
The paper analyzes the constitutional and legal reforms at the federal and local level, about gender parity in candidacies. Scenarios that would allow effective access to elected positions are anticipated.

Possibilities of the amendments that were introduced by federal entities havin elections on 2015 are studies. A significant increase in the amount of elected women at the county level is expected.
\end{abstract}




\section{Introducción}

La reciente reforma electoral constitucional, publicada en el Diario Oficial de la Federación el 10 de febrero de 2014, reconoce una demanda que durante décadas se venía gestando: la paridad en las candidaturas.

El Constituyente consideró que no bastaba con reformar una ley sustantiva en materia electoral. Fue más a fondo. Decidió reformar pero a nivel constitucional, haciendo con ello suyos estándares internacionales. De ahí que ahora el artículo 41 de la carta magna establece como obligación de los partidos políticos hacer posible el acceso de los ciudadanos al ejercicio del poder público de acuerdo a la regla que garantiza la paridad entre los géneros, en candidaturas a legisladores federales y locales. ${ }^{1}$

Este sentir se vio fortalecido con la aprobación del reciente decreto que expide la Ley General de Instituciones y Procedimientos Electorales, ${ }^{2}$ la cual, en su artículo 232, párrafo 4, señala que el Instituto Nacional Electoral y los organismos públicos locales electorales tendrán en el ejercicio de sus competencias, facultades para rechazar el registro del número de candidaturas de un género que exceda la paridad, fijando al partido un plazo improrrogable para la sustitución de las mismas y que, en caso de que no sean sustituidas no se aceptarán dichos registros.

El camino hacia la paridad no fue sencillo. Fue una lucha de muchas mujeres que batallaron para hacer respetar sus derechos. Este no solo fue un esfuerzo de nivel nacional, sino que intervinieron muchos factores como instrumentos internacionales, acciones afirmativas, asociaciones civiles, hasta que llegamos a pronunciamientos jurisdiccionales que tutelaron el tan anhelado derecho a la igualdad y no discriminación en la participación política de las mujeres.

La buena noticia es que ese propósito no quedó en el ámbito federal. Derivado de los principios incorporados a la norma constituyente, en las legislaciones locales de las entidades que tendrán elecciones en 2015 hay, ahora, disposiciones que obligan a la paridad en las legislaturas y, en casi todos los casos, también en la elección de ayuntamientos.

1 Código de Buenas Prácticas en Materia Electoral de la Comisión Europea para la Democracia a través del Derecho (Comisión de Venecia).

2 Aprobado por la Cámara revisora (Cámara de Diputados) el 15 de mayo de 2014. 


\section{Política de paridad}

Las reformas constitucionales y legales avanzan en el sentido correcto, pues ponen al país en el camino hacia la construcción de una política de paridad en la que hombres y mujeres puedan compartir, en iguales proporciones, el poder público.

Este anhelo nos lleva a la reflexión de dos transiciones conceptuales que han tenido lugar en épocas recientes. Por un lado, el tránsito a la igualdad sustantiva, mediante la cual se abandonó la idea de que basta con reconocer la igualdad entre hombres y mujeres en la ley (igualdad formal), para dar lugar a nuevos estadios en los que se requiere la igualdad en los resultados (igualdad sustantiva). De ahí que se diera el cambio a la igualdad formal, el cual logró que las leyes reconocieran iguales derechos y obligaciones para hombres y mujeres. Esa noción años más tarde logró materializarse en el principio de igualdad que actualmente es recogido en 172 Constituciones del mundo.

La segunda transición es más ambiciosa. Se propone avanzar hacia un nuevo contrato social en el que ambos sexos compartan el poder en todos los espacios decisionales.

Por lo pronto, hay varias experiencias paritarias en el mundo en las que se han logrado construir reglas para la participación de unas y otras en cuerpos electivos. ${ }^{3}$

\begin{tabular}{|c|c|l|}
\hline País & Año & \multicolumn{1}{|c|}{ Sanción } \\
\hline Francia & 2000 & $\begin{array}{l}\text { Reducción del subsidio público equivalente al 75\% de } \\
\text { la diferencia del porcentaje de candidaturas de hom- } \\
\text { bres y mujeres, en caso de que ese sea superior al 2\% } \\
\text { (CB). Invalidación de la lista (CA) }\end{array}$ \\
\hline Bélgica & 2002 & No inscripción de la lista \\
\hline España & 2007 & No inscripción de la lista \\
\hline Ecuador & 2008 & No inscripción de la lista \\
\hline Bolivia & $2009 / 2010$ & $\begin{array}{l}\text { No inscripción de la lista y plazo de 72 horas para sub- } \\
\text { sanar }\end{array}$ \\
\hline Costa Rica & 2009 & No inscripción de la lista \\
\hline Senegal & 2010 & Descalificación del Proceso electoral (CB) \\
\hline
\end{tabular}

3 Unión Interparlamentaria, Igualdad en la política: un estudio sobre mujeres y hombres en los parlamentos. Reportes y documentos, núm. 54, 2008, p. 25. 


\begin{tabular}{|c|c|l|}
\hline País & Año & \multicolumn{1}{c|}{ Sanción } \\
\hline Túnez & 2011 & $\begin{array}{l}\text { No inscripción de la lista (no aplica cuando el número } \\
\text { de escaños es impar y no se puede implementar estric- } \\
\text { tamente el 50\%) }\end{array}$ \\
\hline Nicaragua & 2012 & No establece sanción \\
\hline México & 2014 & No inscripción de candidatos \\
\hline
\end{tabular}

Si bien es Francia el país que inició con el tema, paradójicamente es América Latina la región que más países paritarios tienen. Entre 2008 y 2009 tres países adoptaron cuotas de candidaturas del 50\%. A ellos se añadió Nicaragua en 2012, y México en 2014.

A ese incremento en las cuotas han seguido otros elementos, como la imposición de sanciones a quienes incumplan la nominación de 50\% de candidatas, pasando desde la reducción de prerrogativas, las multas o el no registro de candidaturas.

En otras naciones de América Latina, como Honduras y Panamá, las reglas de paridad operan en el nivel de las elecciones primarias de los partidos. Hay, evidentemente, movimientos sociales que claman por su traslado hacia las candidaturas.

En esa tesitura de ideas es que se deben revisar los alcances y límites de las reformas recientemente aprobadas por los congresos federal y locales.

\section{Reformas a nivel federal}

A continuación se recuperan los principales elementos de las reformas a la Constitución Política de los Estados Unidos Mexicanos y de la naciente Ley General de Instituciones y Procedimientos Electorales.

\section{Magnitud de la cuota}

El cambio más evidente fue en el tamaño de la cuota. La Constitución y la Ley Electoral de Instituciones y Procedimientos Electorales fijan una cuota paritaria, tanto para el Senado como para la Cámara de Diputados.

El incremento de la cuota al 50\% completa ese largo ciclo que inició en 2002, cuando se instauraron las cuotas obligatorias en el país: 30\% para el registro de candidaturas en ambas cámaras. Con esa cuota, se alcanzaban apenas tasas de representación cercanas al 20\%. 
La cuota se incrementó al 40\% con la reforma electoral de 2007-2008, pero la representación de mujeres no lograba pasar el 30\% que convencionalmente se acepta como necesario para generar cambios cualitativos en la manera de hacer política.

Fue hasta la pasada elección, y no como producto de un nuevo incremento en las cuotas, que en México se alcanzó a rebasar ese umbral. Lo cierto es que la nueva cuota del $50 \%$ es histórica y pone al país en ese selecto grupo de naciones que consideran una medida de ese tamaño.

\section{Suplencias en las fórmulas}

El segundo cambio importante que propone la reforma es que propietarios y suplentes deben ser del mismo sexo. Lo mismo ocurre para candidatos de partido como para candidatos independientes.

Cabe la pena recordar el caso de 2009, cuando diez diputadas recién electas renunciaron a sus cargos para ceder sus lugares a sus suplentes varones.

A fin de evitar esa situación de acoso político, en 2012 el IFE propuso en sus lineamientos de candidaturas que titulares y suplentes fueran del mismo sexo.

Curiosamente, esa disposición fue impugnada ante el Tribunal Electoral en el expediente SUP-JDC-12624/2011, donde las actoras hicieron ver que eso podría no convenirles. Explicaron que la única manera en que una cuota cualesquiera pudiera tender a la paridad ya en el ejercicio del cargo sería si ellas pudieran ser suplentes de varones.

Así que el Tribunal Electoral determinó que las mujeres tendrían que tener suplentes mujeres, pero los hombres podrían tener suplentes de cualquier sexo.

El tiempo dio la razón a esa postura. Hoy la representación de mujeres ha crecido ligeramente. Hay dos diputadas y una senadora más que cuando fueron electas en 2012, como consecuencia de aquellos hombres que renunciaron para aspirar a otros cargos y fueron suplidas por mujeres.

\section{Eliminación de la excepción}

Un párrafo después de establecer las cuotas de género, el Código Federal de Instituciones y Procedimientos Electorales las nulificaba al permitir una excepción en aquellos casos donde los candidatos se eligieran en "procesos de elección democráticos". 
Ese fue el mérito de la aludida resolución SUP-JDC-12624/2011, pues al detectar que por definición, todos los procesos emanados de los partidos políticos son democráticos, resolvió eliminar cualquier excepción y obligar a que los partidos cumplieran la cuota prevista en la ley. Tal decisión fue celebrada por el Comité de Expertas de la CEDAW cuando reconoció que se había dejado sin efecto el aspecto que más mermaba el desempeño de sus acciones afirmativas.

La nueva Ley General de Instituciones y Procedimientos Electorales pone fin a esa discusión, al no incorporar excepción alguna para el cumplimiento de la cuota. Con ello se contribuye a dar eficacia al instrumento.

\section{Mayoría relativa ${ }^{4}$}

Uno de los avances que se encuentra más allá de la estipulación del 50\% de candidaturas de un género se encuentra en el artículo 3o. de la Ley General de Partidos cuando aborda uno de los temas que más preocupaban cuando se hizo la reforma: el hecho de que, a pesar de las cuotas, los partidos tienen la posibilidad de postular a mujeres en aquellos distritos que consideran perdedores.

Por eso es relevante que el ordenamiento que regula la actividad partidista expresamente prohíba a esos institutos políticos adoptar como estrategia la de postular a mujeres candidatas en aquellos distritos que se identifican como perdedores.

Conviene precisar que en un ejercicio para ver a quién postularían como candidato en 2009, aquellos partidos que ganaron algún distrito en 2006, se encontró que en 200 de los 300 casos, los candidatos propuestos fueron varones. Es decir, existe una tendencia a privilegiar candidaturas masculinas en los distritos que tienen buenas expectativas de ser ganadores.

De ahí la importancia de que explícitamente se haya incluido en la ley la imposibilidad de usar ese tipo de criterios.

\footnotetext{
4 Ley General Partidos Políticos. Artículo 3...

4. Cada partido político determinará y hará públicos los criterios para garantizar la paridad de género en las candidaturas a legisladores federales y locales. Éstos deberán ser objetivos y asegurar condiciones de igualdad entre géneros.

5. En ningún caso se admitirán criterios que tengan como resultado que alguno de los géneros le sean asignados exclusivamente aquellos distritos en los que el partido haya obtenido los porcentajes de votación más bajos en el proceso electoral anterior.
} 


\section{Representación proporcional $\left.\right|^{5}$}

Otro punto interesante a destacar es la representación proporcional. Los estudios en la materia han demostrado que las cuotas de género tienen mucha mayor efectividad en los sistemas de representación que en los de mayoría. ${ }^{6}$

En países como México, donde la proporcionalidad ocupa una fracción importante de la representación popular, vale la pena tener en claro este tema.

En el pasado había segmentos. Primero, en 2002, se decía que segmentos de tres, en los que una persona debía ser de distinto sexo. En 2007, segmentos de cinco, donde dos personas debían ser de distinto sexo que los otros tres. Además, debían alternarse.

En las elecciones de 2009, un partido político mexicano interpretó que esa alternancia podría construirse hombre-hombre-hombre-mujermujer, por lo que una candidata que ocupaba el 4o. lugar en su segmento impugnó y forzó a que la jurisdicción interpretara que, evidentemente, la alternancia implica que los sexos se intercalen dentro de cada segmento: mujer-hombre-mujer, y así sucesivamente. ${ }^{7}$

La nueva disposición va más allá de esa interpretación al establecer un sistema de cremallera, sin segmentos, en los que los sexos deben intercalarse.

Ante la evidencia de que las listas suelen empezar con varón, hubiera sido deseable alguna regulación que obligara a los partidos a iniciar algunas de sus listas con hombres y otras con mujeres.

\section{Senado}

La reforma político electoral publicada en febrero pasado establece un porcentaje del $50 \%$ para el registro de candidaturas. Ahora bien, para la integración del Senado también se tendrá que cuidar que se respete el ac-

5 Ley General de Instituciones y Procedimientos Electorales. Artículo 234.

1. Las listas de representación proporcional se integrarán por fórmulas de candidatos compuestas cada una por un propietario y un suplente del mismo género, y se alternarán las fórmulas de distinto género para garantizar el principio de paridad hasta agotar cada lista.

6 IDEA, Making Gender Quotas Work.

7 SUP-JDC-161/2009. 
ceso a los cargos. Aquí sí existen problemas en el diseño, cuando menos en el caso de la mayoría relativa.

A través de ese principio se eligen dos senadores. Cada partido postula dos candidatos con sus respectivos suplentes por estado. Se otorgan dos senadores a la mayoría y uno a la primera minoría.

Ello abre la posibilidad a una distorsión, pues se corre el riesgo de que se postule a puro varón al inicio de las listas de mayoría relativa y a mujeres en la segunda posición. Con ello, los partidos que obtengan dos lugares aportarían puro varón al Senado, con lo que una configuración de candidaturas del $50 \%$ podría traducirse en la práctica, en una representación de mujeres en el Senado muy pequeña.

\section{Sanciones por incumplimiento de cuota}

Otro aspecto a destacar es que la nueva Ley de Instituciones y Procedimientos Electorales retomó sanciones enérgicas al incumplimiento de sus cuotas. ${ }^{8}$

Con ello, evita ese limbo en el que quedan aquellas disposiciones que - por duras que sean- no tienen sanción y, por ende, generan incentivos para ser incumplidas. También evita eso que pasó alguna vez con las cuotas en Francia que, al imponer una multa pecuniaria a quienes la incumplían, dejaban a los partidos en posibilidad de hacer cuentas para saber si mejor pagaban la sanción, para poder postular más hombres que los autorizados por la norma.

Al obligar al INE a no registrar las candidaturas que incumplan la cuota, la ley recupera esa experiencia de 2012 cuando los partidos explicaron que no encontraban candidatas con quién llenar las candidaturas. Cuando el IFE salió a medios a decir que no registrarían las candidaturas de quienes incumplieran la 12624, rápidamente hallaron a las candidatas mujeres y las registraron en tiempo y forma.

8 Ley General de Instituciones y Procedimientos Electorales. Artículo 235.

1. Hecho el cierre del registro de candidaturas, si un partido político o coalición no cumple se le requerirá en primera instancia para que ... rectifique la solicitud de registro de candidaturas y le apercibirá de que, en caso de no hacerlo, le hará una amonestación pública.

2. Transcurrido el plazo a que se refiere el párrafo anterior, el partido político o coalición que no realice la sustitución de candidatos, será acreedor a una amonestación pública y el Consejo General le requerirá, de nueva cuenta, para que en un plazo de veinticuatro horas, contadas a partir de la notificación, haga la corrección. En caso de reincidencia se sancionará con la negativa del registro de las candidaturas correspondientes. 


\section{Formación de liderazgos}

Desde 2008, el Cofipe consideraba un 2\% del financiamiento público destinado a promover liderazgos femeninos, tal y como ocurre en Costa Rica, Brasil, y Panamá.

A falta de una reglamentación precisa, algunos partidos quisieron justificar ese gasto en pago de secretarias o de materiales de oficina. Una sentencia del Tribunal clarificó que el pago debía ser directamente benéfico para fortalecimiento de liderazgos femeninos.

Al poco tiempo el IFE expidió unos lineamientos que recuperaban esa decisión y precisaban qué rubros de gasto podrían servir para comprobar el ejercicio del famoso $2 \%$.

La nueva disposición no solo incrementa en un 50\% el monto del financiamiento para fomentar liderazgos de mujeres, sino que además propone algunos renglones de gasto aplicable. Ahora la Ley General de Instituciones y Procedimientos Electorales ${ }^{9}$ prevé un aumento en el porcentaje destinado a la capacitación, promoción y el desarrollo del liderazgo político de las mujeres del 3\% del financiamiento público ordinario.

Además, la Ley General de Partidos Políticos propone un catálogo exhaustivo de los rubros que se pueden justificar con ese recurso, con lo que evita que se destinen a rubros ajenos a la promoción del liderazgo político de las mujeres.

\section{Vida interna de los partidos ${ }^{10}$}

Se debe celebrar que la Ley General de Partidos Políticos impone la obligación de que las normas partidistas les obliguen a promover la igualdad de oportunidades y equidad entre hombres y mujeres.

9 Ley General Partidos de Políticos.

Artículo 51. Para la capacitación, promoción y el desarrollo del liderazgo político de las mujeres, cada partido político deberá destinar anualmente, el tres por ciento del financiamiento público ordinario.

Artículo 73. Los partidos políticos podrán aplicar los recursos... en los rubros siguientes:

a) La realización de investigacion... [sobre] liderazgo político de la mujer;

b) ... libros, revistas, folletos... [sobre] paridad de género;

c) ... mesas de trabajo, conferencias, [sobre] el desarrollo de la mujer en su incorporación a la vida política;

d) ... propaganda y publicidad relacionada con... la materia, y

e) Todo gasto necesario para la organización y difusión de las acciones referidas.

10 Ley General de Partidos Políticos. 
No se debe dejar pasar como desapercibido que la disposición en la que se les obliga a "buscar la participación efectiva de los géneros" en sus dirigencias y candidaturas es más tenue que muchos estatutos partidistas que ya se autoimponen cuotas en dirigencias.

\section{Reformas a nivel local}

Las reformas constitucional y legal recientes tienen obligaciones en materia de igualdad de género tanto para la federación como para los estados y el Distrito Federal. De ahí que se haya detonado un proceso de homologación que está sirviendo para poner al día las disposiciones de cada entidad.

Asimismo, está sirviendo para cumplir con una recomendación que hizo a México el Comité de Expertas de la Convención para la Eliminación de Todas las Formas de Discriminación contra la Mujer (CEDAW) en el sentido de homologar las leyes y de garantizar la efectividad de los sistemas de cuotas.

A continuación se presentan los primeros hallazgos de un estudio comparado sobre cómo están siendo impactadas las disposiciones de género en las legislaciones locales de las 17 entidades con elecciones ordinarias en 2015 por sistemas de partidos. ${ }^{11}$ Todas ellas ya aprobaron cambios constitucionales y legales. De las 15 entidades que no tienen elecciones en 2015, cuatro ya aprobaron reformas constitucionales: Chihuahua, Durango, Hidalgo y Zacatecas. ${ }^{12}$

Un dato relevante se presentó en el estado de Nuevo León, entidad federativa que fue de las últimas en emitir su legislación correspondiente, lo que evidentemente incluye al apartado de paridad. Ante tal situación una ciudadana decidió impugnar la omisión legislativa, la Sala Superior estimó procedente el sobreseimiento en virtud de que entre el tiempo de

Artículo 37. Los partidos políticos promoverán los valores cívicos y la cultura democrática entre niñas, niños y adolescentes, y buscarán la participación efectiva de ambos géneros en la integración de sus órganos, así como en la postulación de candidatos.

La declaración de principios contendrá, por lo menos...

e) La obligación de promover la participación política en igualdad de oportunidades y equidad entre mujeres y hombres.

11 Oaxaca tiene elecciones por sistemas normativos tradicionales, pero no reformó su legislación local.

12 Datos al 16 de julio de 2014. 
la presentación del medio de impugnación y su resolución el Congreso del Estado emitió la legislación.

Si bien hubo acuerdo en ese desechamiento, quienes estuvimos en la posición minoritaria pensamos necesario reconocer que la ciudadana actora sí tenía interés legítimo para la controversia. El nuevo paradigma constitucional establece la situación especial de grupos tradicionalmente desprotegidos, como las mujeres, para inconformarse ante acciones $\mathrm{u}$ omisiones que colocan al grupo en una situación de desigualdad jurídica.

\section{Cuotas de género en las legislaturas}

El tema de las legislaturas locales es relevante, ya que en el país apenas hay 305 diputadas locales. Es decir 26.8\% del total. De las entidades con elecciones en 2015, todas incluyeron preceptos de paridad en sus Constituciones, utilizando para ello el verbo "garantizar". Quedaron lejos las simulaciones donde "procurar" o "intentar" dejaban abierta la puerta para el incumplimiento. Además, eliminaron los segmentos en las listas de representación proporcional, de manera que encontraremos en los estados también un sistema de cremallera.

Pero vale la pena recuperar lo dicho al principio de este artículo. Tan importante como el tamaño de la cuota, es su diseño. Ello quedó demostrado en la elección local de Coahuila de 2014, donde ya aplicó la fórmula paritaria. Ese estado cuenta con 16 diputaciones por mayoría relativa de las cuales resultaron ganadoras 8 mujeres y 8 varones. $50 \%$ de conformidad a su cuota.

Para representación proporcional se cuenta con 9 curules a repartir entre 9 partidos locales. Puesto que un partido ganó en todos los distritos electorales, no se le consideró para la asignación de diputados de representación proporcional. Al momento de efectuar el reparto, conforme a las bases estatales, se presentó que a los nueve partidos que no obtuvieron un triunfo por mayoría relativa se les asignó únicamente un diputado.

Ahí se hizo claro un problema de diseño, ya que la inmensa mayoría de partidos postularon en el primer lugar de sus listas a varones. Al lograr la diputación apenas un candidato de cada fuerza política, las diputaciones de representación proporcional se hicieron abrumadoramente masculinas. Ello, a pesar de que las listas sí consideraban un sistema de cremalleras que alternaba hombre-mujer-hombre, etcétera. Este hecho generó que solo el $11 \%$ de los diputados por representación proporcional fueran mujeres. 


\section{Excepciones}

Como ocurrió en el caso de la norma federal, en las locales prácticamente se eliminaron las excepciones que pudieran mermar el desempeño de la cuota. Solo en los casos de Chiapas, Colima y Morelos, sus legislaciones nuevamente encontraron excepciones a las cuotas.

\section{Suplencia}

En cuanto a las reglas de suplencia, en general se sigue el modelo de la legislación federal, según el cual las fórmulas deben estar integradas por personas del mismo sexo.

Hubo dos casos atípicos que recogen precedentes del Tribunal: Chiapas y Yucatán que evita que las mujeres tengan suplentes hombres, al tiempo que les reconoce la posibilidad de sí sustituir a varones. Se trata de una muestra de legislación desde una perspectiva de género. ${ }^{13}$

\section{Sanciones}

Una buena contribución de la Ley General de Instituciones y Procedimientos Electorales es que obliga a los organismos públicos locales a sancionar, inclusive con la pérdida del registro, a aquellos partidos que no cumplan con los criterios de paridad en el registro de candidaturas. ${ }^{14}$

En los casos de Michoacán y Morelos no se halló sanción alguna al incumplimiento de la cuota.

13 Ley Electoral de Yucatán. Artículo 214.

...

II. Con objeto de que la representación popular en el Poder Legislativo del Estado se de en condiciones de paridad, y en los ayuntamientos se de en condiciones de equidad de género...

d) Tratándose de fórmulas en que el candidato propietario sea del género femenino, los suplentes deberán ser del mismo género.

14 Ley General de Instituciones y Procedimientos Electorales del Estado de Chiapas. Artículo 232.

4. El Instituto y los Organismos Públicos Locales, en el ámbito de sus competencias, tendrán facultades para rechazar el registro del número de candidaturas de un género que exceda la paridad, fijando al partido un plazo improrrogable para la sustitución de las mismas. En caso de que no sean sustituidas no se aceptarán dichos registros. 


\section{Ayuntamientos}

Una buena noticia de este apartado es la de los ayuntamientos. Lo es, sobre todo, porque en México siete de cada 100 presidentes municipales son mujeres. La disposición constitucional sobre paridad es expresa en cuanto a los congresos federal y local, pero no así para ayuntamientos.

No obstante, hay algunas disposiciones que sí serían indicativas de la necesidad de establecer criterios paritarios en otros cargos de elección. Un aspecto a destacar es que todos los estados analizados mencionen alguna cuota de género vertical en sus ayuntamientos. La amplia mayoría va por la paridad.

Dos casos de esto último, los encontramos en Chiapas y el Distrito Federal; en el primero para la asignación de regidores de representación proporcional se deben observar dos reglas:

a) La lista de candidatos a regidores de representación proporcional deberá ser encabezada por una mujer.

b) Cuando el número de cargos a asignar sea impar, se rompe la paridad en favor de las mujeres, pues el mayor número de estos cargos corresponderá al género femenino.

En el caso del Distrito Federal, la cuota funciona de manera horizontal. Es decir, los partidos políticos deben postular un 50\% de candidatos de cada sexo para jefes delegacionales.

Es sorprendente el caso de Nuevo León que solía encontrarse rezagado, al no tener una cuota para el Congreso, aunque ciertamente había disposiciones al nivel de ayuntamientos. Ahora, la paridad del Congreso se ve complementada con una disposición que obliga al 50\% de candidaturas en ayuntamientos. ${ }^{15}$

\section{Indígenas}

El principal faltante de las reformas electorales locales en materia de género: la representación de mujeres indígenas. En México es posible ad-

15 Artículo 112. La solicitud de registro de candidaturas deberá señalar el partido político o coalición que las postulen y los siguientes datos de los candidatos:

VII. La solicitud de registro para los cargos de elección popular, tratándose de planillas en la renovación de Ayuntamientos, en ningún caso la postulación de candidatos debe contener más del setenta por ciento de candidatos propietarios de un mismo género... 
vertir casos donde las mujeres son excluidas, a veces argumentando normas consuetudinarias que será necesario revisar.

A este respecto, vale la pena recuperar una sentencia reciente del Tribunal Electoral del Poder Judicial de la Federación, donde se controvirtió la elección de una comunidad indígena que excluyó a las mujeres del proceso electivo, argumentando que tal era la tradición local. Después de hacer los estudios correspondientes, la justicia electoral encontró que que ni siquiera había tales costumbres. Había sido la autoridad del momento la que lo había inventado.

Se ordenó reponer el procedimiento. Cuatro mujeres fueron electas regidoras. Ahora son responsables de las carteras de educación, salud, ecología y alumbrado.

\section{A manera de conclusión}

La reforma constitucional cumple con un gran objetivo, al proponer la paridad como eje de las candidaturas al Congreso, tanto a nivel federal como local. Además, establece una serie de principios ecualizantes que abonan hacia una vida política más igualitaria, dentro y fuera de los partidos.

Por eso no es de sorprender que las legislaturas locales hayan adoptado también la paridad para los ayuntamientos, ya que hay disposiciones que expresamente obligan a pensar en iguales posibilidades para hombres y mujeres en los cargos electivos.

La apuesta es ambiciosa pero sin duda trastocará el escenario político del país. Quizás en algunos años, este anhelo por mayores candidaturas de mujeres se traducirá en nuevos liderazgos políticos, más opciones para los votantes y mejor representación de nuevas ideas en los cuerpos colegiados.

El paso siguiente, sin duda, estará en la manera de hacer política. No basta con garantizar que más mujeres lleguen a los espacios públicos. Para que la participación de las mujeres se traduzca en nuevos resultados, es necesario asegurar que tengan incidencia en su desempeño. Para eso será necesario ir creando reglas que hagan igualitaria la manera de hacer política, dentro y fuera de los Congresos.

Lo importante es que se ha dado el paso para una nueva política de paridad en la que hombres y mujeres sean corresponsables de la toma de decisiones. Ello enriquecerá la construcción de políticas públicas al incorporar visiones que antaño estaban excluidas. 


\section{Bibliografía}

Alanis, María del Carmen, "Votar y juzgar con perspectiva de género", Revista Quid Iuris, núm, 14, 2011.

- - , Jurisprudencia, reformas constitucionales y legales en materia electoral (mujeres e indígenas), tesis de doctorado, UNAM, 2013.

Aquino de Souza, Cristiane, "La legitimidad de la democracia y la política de la presencia”, Doxa, Cuadernos de Filosofía del Derecho, 33, 2010.

Cook, Rebeca y Cusack, Simone, Estereotipos de género, perspectivas legales transnacionales, Filadelfia, University of Pennsylvania Press, 2009.

Dahl, Robert, On Political Equality, Estados Unidos, Yale University, 2006.

FAcio, Alda, "Con los lentes de género se ve otra justicia”, El Otro Derecho, Bogotá, núm. 28, 2002.

-_-, El acceso a la justicia desde una perspectiva de género, Costa Rica, ILANUD, 2000.

Ferrajoli, Luigi, "La igualdad y sus garantías", en SARlo, Oscar y BlanCO, Andrés (coords.), El principio de igualdad en la teoría del derecho y la dogmática jurídica, Uruguay, Fondo de Cultura Universitaria, 2008.

Nohlen, Dieter, Ciencia política comparada. El enfoque histórico-empírico, México, Benemérita Universidad Autónoma de Puebla-Universidad del Rosario, 2013.

Norris, Pippa y Lena Krook, Mona, Gender Equality in Elected Office. A Six-Step Action Plan, Harvard University-Wasington University in St Louis, 2011.

Phillips, Anne, The Politics of Presence, Oxford, Clarendon, 1993.

SARTORI, Giovanni, Ingeniería constitucional comparada. Una investigación de estructuras, incentivos y resultados", 3a. ed., México, Fondo de Cultura Económica, 2003.

Scherer, Clara, "Las nuevas reglas electorales", Excélsior, 14 de febrero de 2014.

Volden, Craig y Wiseman, Alan, When are Women More Effective Lawmakers than Men, American Journal of Political Science, enero de 2013. 


\section{Legislación}

Código de Elecciones y Participación Ciudadana del Estado de Chiapas. Código de Instituciones y Procedimientos Electorales del Distrito Federal.

Código de Instituciones y Procedimientos Electorales para el Estado de Morelos.

Código Electoral del Estado de Colima.

Código Electoral del Estado de México.

Código Electoral del Estado de Michoacán de Ocampo.

Código Electoral y de Participación Ciudadana del Estado de Jalisco.

Código Federal de Instituciones y Procedimientos Electorales.

Constitución Política de los Estados Unidos Mexicanos.

Ley General de Instituciones y Procedimientos Electorales.

Ley General de Partidos Políticos.

Ley Electoral del Estado de Baja California Sur.

Ley Electoral del Estado de Querétaro.

Ley Electoral del Estado de San Luis Potosí.

Ley Electoral del Estado de Tabasco.

Ley Electoral para el Estado de Nuevo León.

Ley de Instituciones y Procedimientos Electorales del Estado de Campeche.

Ley de Instituciones y Procedimientos Electorales para el Estado de Guanajuato.

Ley de Instituciones y Procedimientos Electorales del Estado de Guerrero.

Ley de Instituciones y Procedimientos Electorales del Estado de Sonora.

Ley de Instituciones y Procedimientos Electorales del Estado de Yucatán. 